\title{
Faster return to work after psychiatric consultation for sicklisted employees with common mental disorders compared to care as usual. A randomized clinical trial
}

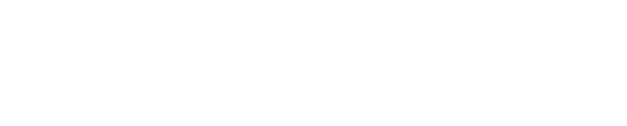

\author{
Christina $M$ van der \\ Feltz-Cornelis' \\ Rob Hoedeman ${ }^{2}$ \\ Fransina J de Jong ${ }^{3}$ \\ Jolanda AC Meeuwissen ${ }^{3}$ \\ Hanneke W Drewes ${ }^{3}$ \\ Niels $C$ van der Laan $^{4}$ \\ Herman J Adèr ${ }^{5}$ \\ 'Department of Developmental, \\ Clinical and Crosscultural Psychology, \\ Tilburg University, Tilburg, \\ The Netherlands; ${ }^{2}$ Department \\ of Health Sciences, University Medical \\ Center Groningen, The Netherlands; \\ ${ }^{3}$ Trimbos instituut, NIMHA, \\ Utrecht, The Netherlands; \\ ${ }^{4}$ Psychiatric Consultation Practice, \\ The Netherlands; ${ }^{5}$ Retired from \\ Department of Clinical Epidemiology \\ and Biostatistics, VU University \\ Medical Center, Amsterdam, \\ The Netherlands
}

Introduction: Return to work (RTW) of employees on sick leave for common mental disorders may require a multidisciplinary approach. This article aims to assess time to RTW after a psychiatric consultation providing treatment advice to the occupational physician (OP) for employees on sick leave for common mental disorders in the occupational health $(\mathrm{OH})$ setting, compared to care as usual (CAU).

Methods: Cluster randomized clinical trial evaluating patients of 12 OPs receiving consultation by a psychiatrist, compared to CAU delivered by 12 OPs in the control group. 60 patients suffering from common mental disorders and $\geq$ six weeks sicklisted were included. Follow up three and six months after inclusion. Primary outcome measure was time to RTW. Intention-to-treat multilevel analysis and a survival analysis were performed to evaluate time to RTW in both groups.

Results: In CAU, referral was the main intervention. Both groups improved in terms of symptom severity and quality of life, but time to RTW was significantly shorter in the psychiatric consultation group. At three months follow up, 58\% of the psychiatric consultation group had full RTW versus $44 \%$ of the control group, a significant finding $(P=0.0093)$. Survival analysis showed 68 days earlier RTW after intervention in the psychiatric consultation group $(P=0.078)$ compared to CAU.

Conclusion: Psychiatric consultation for employees on sick leave in the $\mathrm{OH}$ setting improves time to RTW in patients with common mental disorders as compared to CAU. In further research, focus should be on early intervention in patients with common mental disorders on short sick leave duration. Psychiatric consultation might be particularly promising for improvement of RTW in those patients.

Trial registration number: ISRCTN: 86722376

Keywords: psychiatric consultation, mental disorders, RCT, sickness absence, major depressive disorder, anxiety disorder, somatoform disorder

\section{Introduction}

Sickness absence is a major public health and economic problem, as stated by Henderson et al in their editorial. ${ }^{1}$ Prolonged absence from work and work disability is called the major public health problem in the western world and leads to social deprivation of patients and their families. Long-term sickness absences cover more than a third of total days lost and up to $75 \%$ of absence costs. The contribution of psychiatric disorders to sickness absence has increased remarkably, and nowadays, they account for more
Correspondence: CM van der Feltz-Cornelis

Department of Developmental, Clinical and Crosscultural Psychology, Tilburg University, Tilburg, The Netherlands

Tel +31 I34662167

Email c.m.vdrFeltz@uvt.nl 
incapacity benefit claims than musculoskeletal disorders. Common mental disorders, such as depression and anxiety, contribute most to this rising sickness absence. ${ }^{1}$ While absence from work may provide the patient with more time and opportunity to engage in activities that could contribute to recovery (ie, psychotherapy) and while it may remove the patient from occupational stressors, there are disadvantages to (prolonged) sickness absence. ${ }^{2}$ The ability to work is an important aspect of people's quality of life. ${ }^{3}$ For patients, prolonged absence from work increases the risk of isolation and reduces meaningful activity. ${ }^{4}$ Furthermore, the patient may become anxious to return to work, doubting his own competence and fearing that co-workers will respond with resentment or pity. ${ }^{2}$ Longer absences are associated with a reduced probability of eventual return to work (RTW) and with subsequent economic and social deprivation. ${ }^{1,2}$ Thus, return to work RTW is a very important parameter in occupational health care research.

Common mental disorders, ie, depressive disorders, anxiety disorders and somatoform disorders, are the most prevalent mental disorders. The 12-month prevalence of depression and anxiety are respectively $4.2 \%-7.6 \%$ and $6 \%-12.4 \%{ }^{5,6}$ The prevalence of somatoform disorders is $16 \%$ within the Dutch primary care population ${ }^{7}$ and in international literature a prevalence of $16 \%-33 \%$ has been reported. ${ }^{8}$ Depressive, anxiety and/or somatoform disorders often co-exist. $7,9,10$ They come with the highest burden in terms of work absenteeism and utilization of health care services. ${ }^{11,12}$ Mental problems account for $30 \%$ of disability leave, and in the majority of cases, the employees have never been diagnosed or treated by a psychiatrist. ${ }^{13}$ In case of depressive disorders, $80 \%$ of the costs of this disorder are caused by production loss. ${ }^{14}$ People with major depressive disorders (MDD) are absent from work eight to nine times as much as people without these disorders. ${ }^{15,16}$ Complaints of the musculoskeletal system constitute another $40 \%$ and have been suggested to be possibly partly caused by unrecognized somatoform, depressive or anxiety disorders. ${ }^{17}$ Anxiety disorders such as generalized anxiety disorder (GAD) and panic disorder (PD) also have a high societal impact. ${ }^{18}$ Moreover, work absences caused by mental disorders on average have a longer duration than absences caused by physical illness. ${ }^{19,20}$

Guidelines for evidence-based treatments are available for depressive disorders, for anxiety disorders and for somatoform disorders. ${ }^{21-26}$ However, patients with these disorders are often offered inadequate diagnostic and therapeutic help. ${ }^{27}$ Also, current research shows that a reduction in symptoms does not automatically lead to recovery of functioning at work. ${ }^{28-30}$
In order to achieve a more rapid and more lasting RTW in patients with mental disorders, a focus on functioning at work is essential. ${ }^{29-31}$ However, until now, there has been little research on interventions for patients with common mental disorders specifically aimed at RTW. ${ }^{32}$ Guidelines for mental disorders in occupational health $(\mathrm{OH})$ have been developed by the Netherlands Society of Occupational Medicine (NVAB): the guideline for mental complaints, ${ }^{33}$ and, supplementary to the multidisciplinary guideline for diagnosis and treatment of depression, a module for depression and work. ${ }^{26}$ For somatoform disorders, a guideline has also been developed for the occupational setting. ${ }^{34}$ The NVAB guideline for mental complaints focuses on stress and adjustment disorders in relation to the process of returning to work, functioning and treatment of work-related problems. However, adequate recognition, treatment and criteria for referral for treatment of mental disorders other than adjustment disorders, is not a focus of the guideline. Because of the important role of occupational physician (OPs) in reducing sick leave, ${ }^{35}$ an intervention might be most effective if administered by someone close to the workplace. ${ }^{28,36,37}$ However, OPs in general do not have sufficient knowledge of diagnosis and treatment of mental disorders, as their guidelines focus on a process approach aimed at RTW, and on advice to refer patients to a mental health professional or back to their general practitioner (GP) in case of mental problems. In addition, mental health professionals working in primary care or in mental health institutions in general are not adjusted to accommodating workers who need an intervention aimed at RTW. Therefore, for improvement of occupational rehabilitation of employees on sick leave for mental disorders, a multidisciplinary approach may be needed, in which the domains and competences of OPs and psychiatrists are combined. For this purpose, a psychiatric consultation model might be useful. Psychiatric consultation has been proven effective in the general practice setting in supplying patients with mental disorders with adequate treatment outside of the mental health setting. ${ }^{38,39}$ It might also be effective in the $\mathrm{OH}$ setting. Therefore, in this study, the concept of psychiatric consultation with a focus on RTW in the $\mathrm{OH}$ setting is explored. Treatment is administered by the OP, after consultation by a psychiatrist. Stimulating patients to return to work requires an activating intervention that encompasses specific interventions tailored to the needs created by the specific common mental disorder that the patient suffers from. The primary aim of the current study is to test the effectiveness of psychiatric consultation aimed at diagnosis and treatment of common mental disorders in employees on sick leave with a focus on RTW, as compared to care as usual (CAU). 


\section{Method}

\section{Design}

The study is a two-armed cluster-randomized pragmatic clinical trial with computer-generated random allocation between OPs. The study was performed in collaboration with two occupational health services (OHS) related to various companies. All OPs, in the intervention and in the control group, followed a training program aimed at diagnosis and treatment of patients with common mental disorders on sick leave. As this intervention cannot be blinded, OPs might apply techniques with control patients that they learned to apply with intervention patients. Randomization between OPs eliminates the danger of this contamination. OPs were allocated to the intervention or CAU group by cluster randomization which was executed after baseline measurement by an independent blinded assistant, using consecutive envelopes with computer-generated random allocation. The sequence was concealed until interventions were assigned by an independent blinded research assistant. The outcome parameters were collected using a self report questionnaire by a blinded research assistant. This procedure has been reported in detail elsewhere ${ }^{40}$ Informed consent was obtained from patients in the study after the nature of the procedure had been fully explained to them. The study was approved by a medical ethical committee (METIGG). The design and methods of this study are described extensively elsewhere. ${ }^{41}$ Data are reported according to the CONSORT statement. ${ }^{42,43}$

\section{Hypothesis}

In a randomized controlled study comparing psychiatric consultation with $\mathrm{CAU}$ by the $\mathrm{OP}$, patients will show greater improvement in the intervention group in terms of time to RTW.

\section{Patient selection}

All patients who had visited the $\mathrm{OP}$ within the last six months were selected from the files and received an information letter describing the purpose of the study together with an informed consent letter for the screening procedure and baseline questionnaires. Additionally, OPs could recommend patients to participate, and they then received the informed consent letter together with the baseline questionnaires. In order to reduce selection bias as much as possible, OPs were informed about their randomization status after inclusion of at least four patients or after a maximum time lag of four weeks after the first inclusion.

\section{Inclusion}

Patients were included after at least six weeks absenteeism, no plan for RTW within another six weeks, and a positive screen on either the Patient Health Questionnaire (PHQ) or the Whitely Index (WI). A PHQ positive screen was determined as a cut off score on one of the subscales of the PHQ as follows: cut off scores $>8$ at the depression subscale, eight or higher on the PHQ subscales for PD or $>3$ on the GAD subscale of the $\mathrm{PHQ}{ }^{44,45} \mathrm{~A}$ WI positive score for somatoform disorders was determined as a cut off score of $>3 .{ }^{46}$

\section{Exclusion}

Employees were excluded from the study if they were suicidal, addicted to drugs or alcohol, psychotic, or suffering from dementia. They were also excluded if they had insufficient knowledge of the Dutch language to complete the questionnaires. Employees who were involved in a legislative procedure for unemployment compensation or who had been on sick leave for longer than 52 weeks were also excluded.

\section{Intervention}

In the present study the following elements are central: (1) training of OPs in diagnosis and treatment of employees with depressive disorders, anxiety disorders or somatoform disorders; (2) supportive psychiatric consultations aimed at delivering a diagnosis and treatment plan, including suggestions for RTW adapted to the specific needs of the patients due to their specific disorder; and (3) training of the consultant psychiatrists to provide not only a diagnosis and treatment plan, but also to provide suggestions for successful strategies aimed at improvement of work functioning in view of the limitations of their mental disorder.

All participating OPs received a training in diagnosis and treatment of common mental disorders, given by a psychiatrist (CFC) and an OP (RH) of the research group. Six psychiatrists were trained in performing the consultations. Their training included providing diagnosis, treatment plans and suggestions aimed at RTW specifically tailored to the mental disorder at hand, by a consultation method in which the psychiatrist speaks to the patient once and reports to the OP by consultation letter. Training was based on a model previously developed for the primary care setting. ${ }^{47}$ The coordination of the follow-up care was the responsibility of the OP. In the intervention group, patients received a consultation by two of the trained psychiatrists in support of the care delivered by the OP; in the CAU group, patients received CAU from their OP. 


\section{Clinical outcome measures}

All the clinical outcome measures were self-administered and assessed at baseline, at three months, and at six months. Primary outcome was time to RTW assessed with item nine of the Medical Outcomes Study Short-Form-20 in combination with the follow up assessment date on the questionnaire. ${ }^{48}$ Complementary to the self report on RTW, we received the date of the sickness report and period to RTW from the database of the OHS. If needed this was also checked at follow up by an interview by one of the researchers (HD); the patient information was leading in this assessment. Special attention was given to finding out if RTW was full and lasting RTW. Time to (lasting) RTW is defined as the period between the onset of sickness leave due to the mental disorder at hand and full RTW, for at least four weeks without partial or full relapse. The total number of days of sick leave at entrance in the study was checked by baseline questionnaire.

Secondary outcome was quality of life assessed with the EuroQol (EQ-5D). ${ }^{49-51}$ Another outcome was severity of the depressive, anxiety and/or somatoform symptoms measured with the subscales of the Symptom Checklist (SCL-90). ${ }^{52}$ Finally, data were assembled on the diagnosis and recommendations given during the psychiatric consultation by a medical audit form filled in after the consultation by the psychiatrists.

\section{Sample size}

In the present study, cluster randomization between OPs, and a multi-level analysis (MLA) with OPs at the first hierarchical level and patients at the second level, is used. The primary outcome measure on which the power calculation is based is time to RTW. We assumed that half of the sick listed employees would not return to work during the follow up time of six months, and that of the remainder, a hazard ratio (HR) of 2.0 (ratio of RTW rates of the intervention group versus the CAU group) would be the smallest clinical and societal relevant ratio. This HR is based on HRs found in comparable studies in primary care on stress-related mental disorders. ${ }^{53,54}$ The power calculation is based on the design effect. This is the factor needed to enlarge the total sample size to reach a same standard error one would reach using a randomization between research subjects and a general linear model (GLM) analysis in the sample. The formula is. ${ }^{55}$

$$
\text { Design effect }=1+(n-1) \rho_{1}
$$

where $\mathrm{n}=$ the mean sample size on the second hierarchical level (patient level in this instance) and $\rho_{1}=$ the intraclass correlation.
If a GLM with repeated measures would be used in a study with randomization between patients, with a variance of 1.0, then a sample size of $2 \times 10$ would be needed for a power of 0.90 . An intraclass correlation of about 1.0 would be acceptable as presumption if the contrast between the experimental conditions would be rather high, that is if the practiced CAU would be different than the consultation intervention as performed in the different practices. We presume that this is the case, as psychiatric consultation to OPs as performed in the present study is a new method for the Netherlands and differs substantially from normal standards of care. ${ }^{20}$ Under these assumptions, in a MLA study such as this one, with a standard deviation (SD) of 1.0, and a mean number of six patients per OP, this would result in a design effect of six. That would mean that $\mathrm{N}$ should be multiplied by six as compared to the number needed for a power of 0.90 in patient-randomised GLM analysis. If in such a study a standardized difference of 1.0 should be detected, a sample size of $2 \times 60$ would be needed in order to detect a clinically relevant significant HR of 2.0 of RTW rates as compared to the rates in the control group. With a design effect of 6 , a sample size of $2 \times 60$ would thus be needed. This is the sample size that we aimed at in the current study. ${ }^{56,57}$

\section{Data analysis}

Intention to treat analysis was performed. Propensity scores were calculated using logistic regression analysis in order to correct for possible bias introduced by the cluster randomization process. After that, MLA was performed with three hierarchical levels: practice level, patient level and time level, with correction for propensity in order to check for possible randomization or selection bias. MLA was applied in order to establish the variance at practice level. Kaplan-Meier analyses were used to describe the association between the sick leave duration in both groups until full RTW and the group allocation. To analyse the HR of the RTW rates the Cox proportional hazard model was used. Chi square tests and a survival analysis were performed on time to RTW in both experimental conditions with the parameters onset of sick leave, and RTW assessed at 3 and 6 months follow up. In the analysis, time lag between onset of sick leave and the intervention was considered as an effect modifier.

\section{Results}

The flow chart of the study is shown in Figure 1. In the original study design, 40 OPs from two $\mathrm{OH}$ setting would participate in the study. Indeed, 41 OPs were trained to participate in the study. Unfortunately, at the start of the inclusion phase, due 


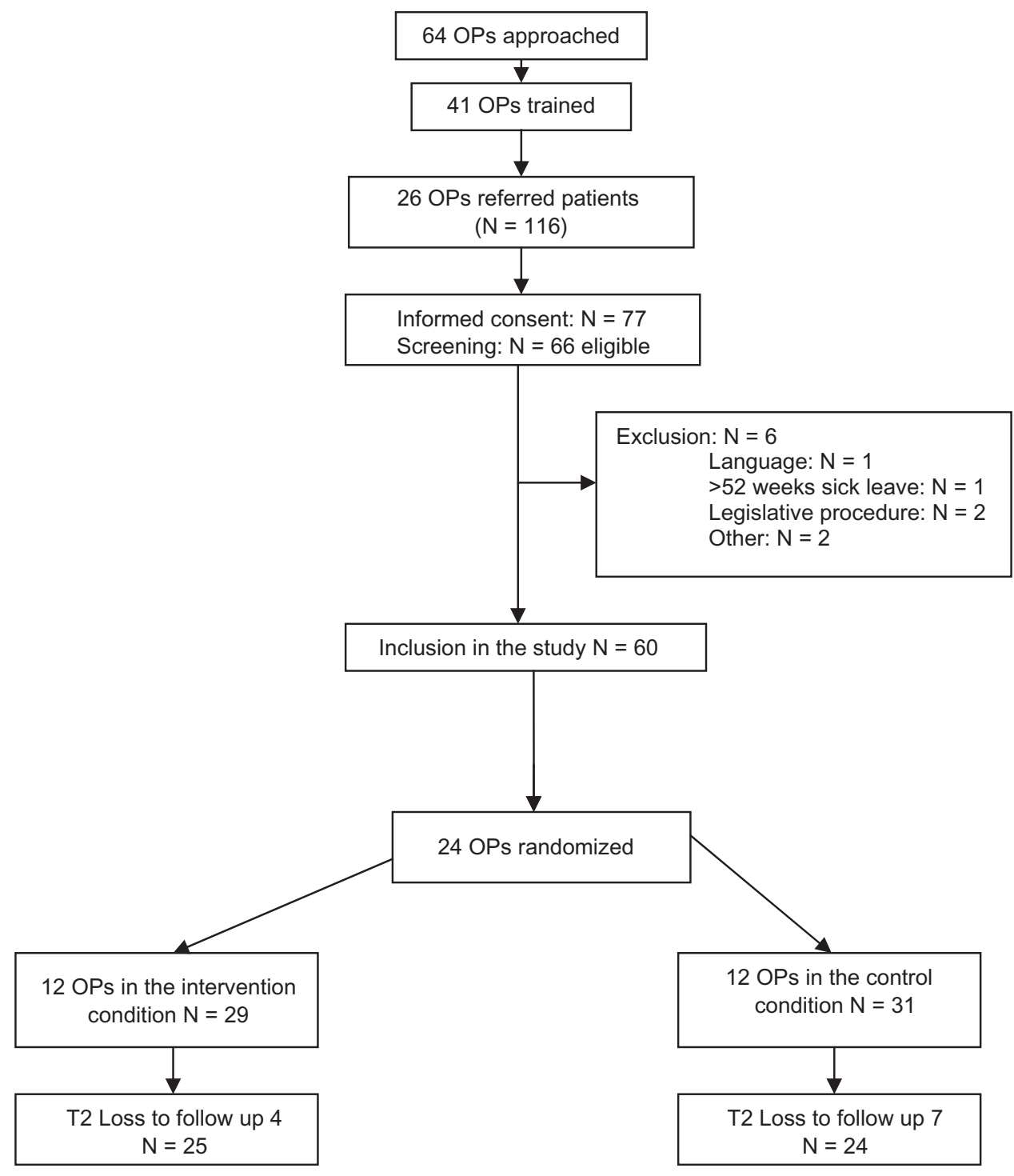

Figure I Consort statement flow-chart of trial. Abbreviation: OP, occupational physician.

to a massive company reorganization with $>1000$ layoffs of employees, including OPs, one of the $\mathrm{OH}$ companies had to cut down on the planned trial collaboration, so that only 26 of these OPs started to refer patients. Because of exclusion of patients, only 24 OPs included patients and were randomly allocated to the intervention or CAU group. In a later phase, still more layoffs occurred and the $\mathrm{OH}$ company was obliged to withdraw from participation in the study altogether. Therefore, patient referral for the study was limited to 116 . Of 116 referred employees on sick leave, 77 gave informed consent. Of these, 66 patients screened positive, but 6 had to be excluded for various reasons as mentioned in the flowchart, leaving 60 patients included for the trial. There was no loss to follow up at three months. At six months, loss to follow up was 11 (16\%). The demographic and baseline characteristics are shown in Table 1.
The mean age was 42 years, range 24-59. The majority were married or living together. Their educational level was fairly high. The demographic characteristics did not significantly differ between the treatment groups. At baseline, MDD and PD as assessed by PHQ were most prevalent. Comorbidity between MDD and anxiety disorders was high. The time between the first day of absenteeism and inclusion in the study ranged from $1-46$ weeks with a mean of 144 days in both groups. Baseline characteristics did not differ significantly between the groups either.

International Standard Classification of Occupations codes of occupational category ${ }^{58}$ were available for 39 patients contributing to the study. The division was as follows: $7 / 39$ (18\%) were legislators, senior officials and managers; $6 / 39(15 \%)$ were professionals, 6 were craft and related trades 
Table I Characteristics at baseline

\begin{tabular}{|c|c|c|c|c|}
\hline Variable & Subcategory & $\begin{array}{l}\text { Total } \\
(N=60) \\
\% M\end{array}$ & $\begin{array}{l}\text { Control } \\
(\mathbf{N}=3 \mathrm{I}) \\
\% \mathbf{M}\end{array}$ & $\begin{array}{l}\text { Intervention } \\
(\mathbf{N}=\mathbf{2 9}) \\
\% \mathbf{M}\end{array}$ \\
\hline \multirow[t]{3}{*}{ Mean age } & & Range & 42 & 42 \\
\hline & & $24-59$ & & \\
\hline & & 42 & & \\
\hline Gender (male) & & 42 & 36 & 48 \\
\hline \multirow[t]{4}{*}{ Civil state } & Single & 18 & 23 & 14 \\
\hline & Married/living & 62 & 55 & 69 \\
\hline & together & & & \\
\hline & Divorced & 18 & 23 & 14 \\
\hline \multirow[t]{3}{*}{ Level of education } & Low & 12 & 17 & 7 \\
\hline & Middle & 47 & 47 & 50 \\
\hline & High & 38 & 37 & 43 \\
\hline \multirow[t]{2}{*}{ Depressive disorder* } & Major depressive disorder & 39 & 35 & 37 \\
\hline & Other depressive disorder & 15 & 13 & 17 \\
\hline \multirow[t]{2}{*}{ Anxiety disorder* } & Generalized anxiety disorder & 13 & 19 & 7 \\
\hline & Panic disorder & 25 & 29 & 21 \\
\hline Somatoform disorder** & & 58 & 55 & 62 \\
\hline Comorbidity between depressive and anxiety disorder* & & 77 & 71 & 83 \\
\hline
\end{tabular}

Notes: *Assessed with the Patient Health Questionnaire. **Assessed with the Whitely Index.

workers, and 6 were technicians or associate professionals; $5 / 39(13 \%)$ were clerks, 5 were service workers and shop and market sales workers; 4/39 (10\%) were manual laborers. Agriculture and fishery workers as well as plant and machine operators were not represented.

\section{Psychiatric consultation}

Psychiatric consultation was performed in the intervention condition, most often between baseline assessment and three months follow up. Two of the six trained psychiatrists were available for the consultations. They would see the patient for the diagnostic interview or perform the interview by telephone, depending on which was more convenient for the patient. During the consultation, the psychiatrist made an inventory of treatments offered to the patient before, and decided together with the patient, if more intensive treatment was needed. This depended on the severity of symptoms, on the perceived well being of the patient and on the level of general functioning as indicated by the Global Assessment of Functioning (GAF) score on Axis V of the Diagnostic and Statistical Manual of Mental Disorders, 4th Edition (DSM-IV). ${ }^{59}$ This system of allocation of care dependent on GAF score has been described more extensively elsewhere. ${ }^{60}$ If necessary, the treatment step was followed up by a step to improve the outcome. This form of process monitoring is a way to practically implement stepped care according to multidisciplinary guidelines. The tool as used by the consultant psychiatrists is derived from an algorithm as previously described in another study. ${ }^{61}$ As it turned out, it was found that in most cases, referral to mental health professionals for some kind of treatment had already occurred, but the mental disorder was not yet in remission. In most cases therefore, advice for change of treatment was given according to the stepped care algorithm.

\section{Care as usual}

In the CAU condition, referral to specialty mental health care professionals was the most frequent treatment mode. This occurred most often between baseline assessment and assessment at three months follow up.

\section{Propensity scores}

In order to correct for possible bias due to the cluster randomization procedure, propensity scores were calculated. Variables that turned out most predictive in treatment assignment were baseline income and baseline functioning. These combined variables gave a $20 \%$ improvement over the expected $50 \%$ treatment assignment propensity. In the following MLA analysis, the patient propensity scores were used as a covariate.

\section{Clinical outcomes}

In the MLA, the variance of the first hierarchical level, OP practices, was almost zero. OPs did not have an impact on the outcome. Other possible confounders, namely age and gender, were checked but turned out to have no impact on the variance. Although total SCL90, Quality adjusted life-year 
Table 2 Mean differences in clinical outcomes between baseline and 6 months FU in both groups

\begin{tabular}{lllll}
\hline $\begin{array}{l}\text { Outcome } \\
\text { measure }\end{array}$ & PC (SD) & CAU (SD) & B (CI) & P \\
\hline PHQ9 & $-4.00(6.94)$ & $-4.708(4.53)$ & $0.913(-2.62 ; 4.45)$ & 0.605 \\
PHQI5 & $-4.05(5.08)$ & $-3.750(4.17)$ & $-0.178(-3.01 ; 2.66)$ & 0.900 \\
SCL-90 & $-2.475(0.73)$ & $-0.305(0.50)$ & $0.03(-0.35 ; 0.4 I)$ & 0.872 \\
QALY & $0.378(0.06)$ & $0.374(0.11)$ & $0.005(-0.05 ; 0.06)$ & 0.869 \\
\hline
\end{tabular}

Abbreviations: $\mathrm{PC}$, psychiatric consultation; $\mathrm{CAU}$, care as usual; $\mathrm{PHQ}$, patient health questionnaire; QALY, quality adjusted life-years; SCL-90, symptom checklist-90; $\mathrm{Cl}$, confidence interval.

(QALY) and PHQ improved in both groups, there was no significant difference on these outcomes between the experimental conditions as shown in Table 2. Educational level was positively related with positive outcome, but there was no significant difference between both treatment groups.

\section{RTW}

Data were checked for recurrence of sick leave after initial RTW, but in none of the cases such a relapse occurred, so if RTW occurred, it was fulltime and sustained RTW in this study. The results for RTW differed among both groups and are shown in Table 3. RTW measures were evaluated as number of days to RTW counted from baseline. At three months
Table 3 Outcomes for RTW

\begin{tabular}{llll}
\hline $\begin{array}{l}\text { Experimental } \\
\text { condition }\end{array}$ & $\begin{array}{l}\text { Baseline N } \\
\text { (and \% of } \\
\text { baseline) of } \\
\text { patients on } \\
\text { sick leave }\end{array}$ & $\begin{array}{l}\text { FU } 3 \text { months } \\
\mathbf{N} \text { (and \% of } \\
\text { baseline) of } \\
\text { patients with } \\
\text { RTW }\end{array}$ & $\begin{array}{l}\text { FU months } \\
\mathbf{N} \text { (and \% of } \\
\text { baseline) of } \\
\text { patients with } \\
\text { RTW }\end{array}$ \\
\hline CAU $(\mathrm{N}=25)$ & $25(100 \%)$ & $\mathrm{II} / 25(44 \%)$ & $2 \mathrm{I} / 25(84 \%)$ \\
$\mathrm{PC}$ & 26 & $\mathrm{I} / 26(58 \%)$ & $22 / 26(85 \%)$ \\
$(\mathrm{N}=26)$ & $(\mathrm{I}) 00 \%)$ & & \\
$\mathrm{P}($ comparing CAU & & $0.0093($ sign) & 0.0574 (n.s.) \\
with PC) & & & \\
\hline
\end{tabular}

Abbreviations: $\mathrm{PC}$, psychiatric consultation; $\mathrm{CAU}$, care as usual; FU, follow up.

follow up, $58 \%$ of the psychiatric consultation group had full RTW versus $44 \%$ of the control group, a significant finding $(P=0.0093)$ At the end of the six months follow up period, RTW was $84 \%$ in the control group and $85 \%$ in the psychiatric consultation group, which was no longer a significant difference $(P=0.0574)$; apparently, RTW occurred in the CAU group as well, but later than in the psychiatric consultation (PC) group. No interaction was found with duration of sick leave before inclusion. In general the duration of sick leave before inclusion in the study was long, mean 144 days. A survival analysis showed that RTW occurred 190 days after the intervention (95\% confidence interval [CI]: 134-246) in

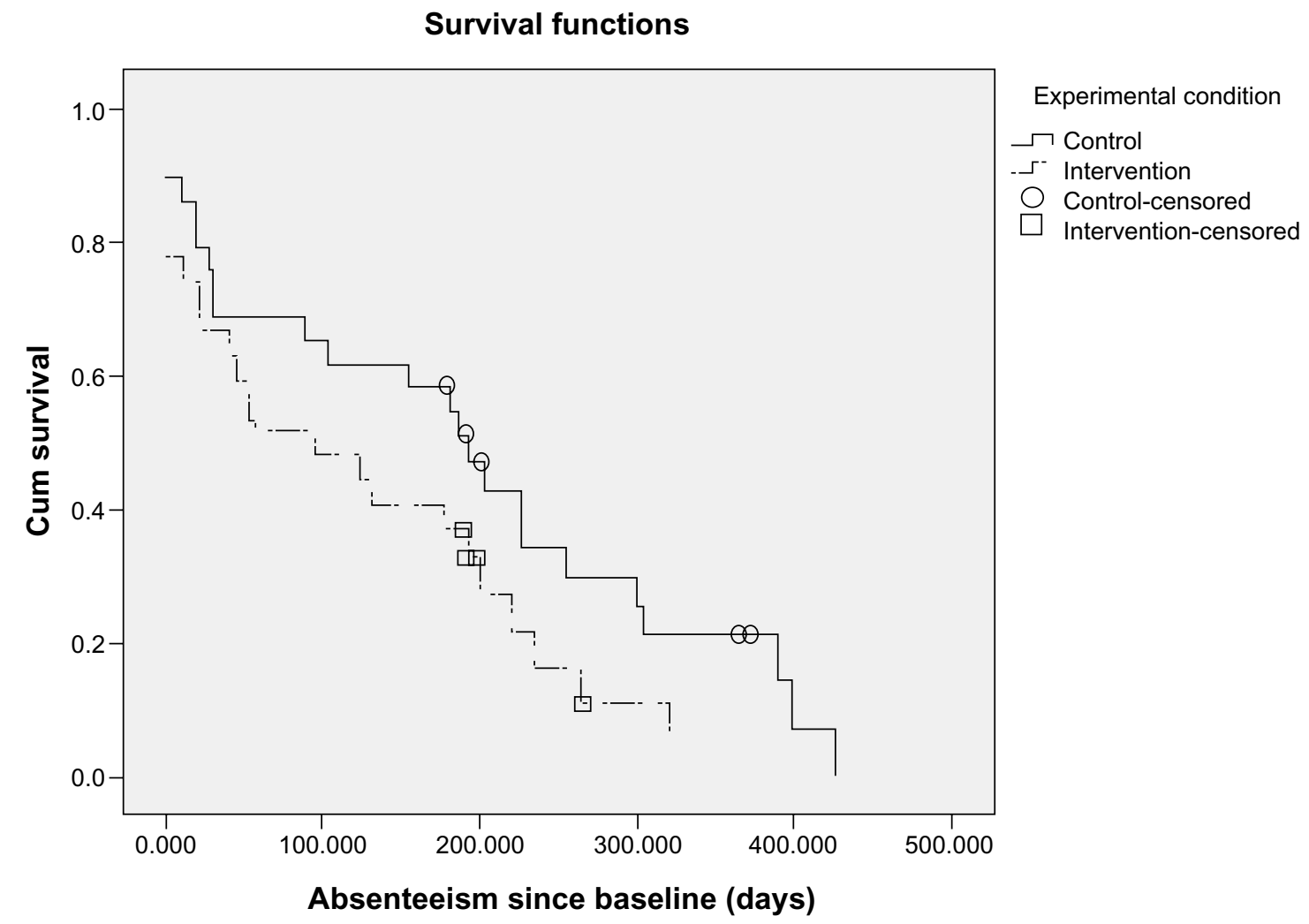

Figure 2 Kaplan-Meier survival curve.

Notes: Vertical axis: time to RTW. Horizontal axis: number of days since intervention. 
the control group and 122 days after the intervention (95\% CI: 77-166) in the psychiatric consultation group, a difference of 68 days (Chi square, 3.101; df $1, P=0.078$ ). The KaplanMeier curve is shown in Figure 2. Note that the curves indicate the probability of absenteeism. Thus, absenteeism times show a statistical trend (0.078) to be longer in the control group, and the chance on absenteeism is larger in the control group than in the intervention group.

\section{Discussion}

\section{Main findings of the study}

This study is the first randomized clinical trial evaluating efficacy of psychiatric consultation in the $\mathrm{OH}$ setting in sicklisted employees with common mental disorders. It reports significantly faster RTW after psychiatric consultation at three months follow up. A higher proportion of workers had achieved RTW by three months in the psychiatric consultation group, namely $58 \%$ versus $44 \%$ in the CAU group. At six months follow up there was no difference between the intervention and control groups in the proportion of workers who had achieved RTW. At that time, in the CAU group, referral to mental health specialists had occurred and $85 \%$ had returned to work in both groups, likely reflecting a ceiling effect. The survival analysis showed that RTW was 68 days faster in the psychiatric consultation group $(P=0.078)$. This was a statistical trend, probably due to the fact that the number of included patients was inadvertently lower than planned in this study. Still, the fact that in this small study the main finding is significant, with a very impressive difference in work absence of 68 days, is of high clinical relevance. The essential finding of this study is therefore that it is possible to achieve faster work return through psychiatric consultation in which the psychiatrist gives the OP advice about treatment, embedded in OP training.

\section{Study limitations}

In this pragmatic randomized clinical trial, efficacy of psychiatric consultation versus CAU was evaluated in terms of time to RTW and in terms of severity of symptoms. The study was hampered seriously by the fact that during the study one of the collaborating $\mathrm{OH}$ companies had to stop collaboration due to serious recurring reorganizations and layoffs. For this reason, the number of included patients aimed for could not be attained. The study population was smaller than anticipated. As a consequence the study may have been underpowered to show small differences.

Another aspect of this pragmatic trial was that CAU was an active intervention, the main intervention in the CAU condition being referral to mental health specialists. This can be explained by the fact that the OPs, by their collaboration to the training program and the inclusion for the study, became aware of the fact that the patients that they selected for the study could have mental disorder. If this turned out to be the case, they often referred the patients for treatment if the patient did not receive psychiatric consultation. Therefore, effects that could be found were probably smaller than in case of a non-active control group. Indeed, in the MLA, both psychiatric consultation and CAU, which was often referral, were shown to be effective in terms of improvement symptom severity and quality of life.

Another limitation of the study was that as a mean, patients were on sick leave for a long time before being included in the study, which may have made it more difficult to return to work within the follow up time frame of six months for some patients. If the study would have had a longer follow up period, outcomes might have been different. Also, time between the first day of absenteeism and inclusion in the study varied from 1-46 weeks with a mean of 144 days. It might be possible that the intervention would be more effective if started earlier in the sick leave period.

Another limitation of the study is that participants were selected from the files and encouraged by their OP to participate. Although the criteria by which they were selected were clear cut, and this process was duplicated by the coordinating OP, this might have lead to selection bias. However, a propensity score analysis was performed and no indications for selection bias were found in this analysis.

Another limitation of the study is that although thorough follow up was performed by questionnaire, by telephone interview by a research assistant, and by checking of date of RTW in files of OP, dates of RTW could be obtained in terms of weeks, not days. However, these estimates were robust enough to enable an analysis with significant result in terms of differences between both experimental conditions.

Furthermore, no active supervision was performed over the compliance of the OP with the consultation advice. The intervention might have been more effective if this would have been the case, as OPs are not used to treatment of mental disorders such as depressive disorders, anxiety disorders and somatoform disorders; in their guideline, most attention is paid to treatment of adjustment disorders.

\section{Strengths of the study}

Notwithstanding the limitations mentioned above, a significant effect could still be established in terms of time to RTW. In the psychiatric consultation group, RTW occurred significantly sooner within a time frame of three months 
follow up. Furthermore, a survival analysis found that RTW occurred 68 days faster in the psychiatric consultation group, which was a trend in terms of level of significance. So, despite the small size of the study, it could be established that psychiatric consultation enhances RTW at a faster rate compared to CAU, which consisted in most cases of referral. The fact that still a significant effect could be found despite the limitations of the study suggests that the effect of psychiatric consultation on RTW can be substantial. The fact that the time to RTW is shorter in the psychiatric consultation group if counted from the inclusion, but that this is not significant, might be explained by the fact that the sickness absence was already a mean 144 days at the moment of inclusion. However, 68 days faster RTW means an almost 10 weeks faster RTW in the psychiatric consultation group. Moreover, this is fulltime RTW without relapse in a follow up period of 6 months. This finding comes on top of an improvement in severity of symptoms and in quality of life that was established in both groups. This makes this study of high clinical relevance.

The care provided in the psychiatric consultation group followed a collaborative care approach: patient tailored care executed within a team of, in the current study, the OP, the patient, the consulting psychiatrist, and in some cases a GP. This is a complex intervention that proved effective in the primary care setting and that also turned out to be feasible in this setting. It also turned out to be just as effective as CAU, most often consisting of referral, in improving symptoms and general functioning, and more effective in improving time to RTW. In addition, it is possible that the training program contributed to the effectiveness of the CAU.

Several mechanisms may play a role in the effectiveness of the psychiatric consultation in enhancing faster RTW. The consultation advice may have had influence on treatment by the GP or on monitoring of sick leave by the OP. The psychiatric consultation also might have had an effect in itself. This could have to do with the establishment of a diagnosis and sharing this information, and information about possibilities for treatment, with the patient and his or her GP and OP. Or it might have to do with the effort to give recommendations for RTW in line with the established diagnosis of the mental disorder at hand. As this is a cluster randomized trial, a correction for possible doctor variance (practices) was made. It was shown that it did not make any difference to the effect size which doctor gave the treatment. Apparently the effect of the intervention stands for itself.

\section{Clinical implications}

Psychiatric consultation is a promising approach that should probably be administered in the $\mathrm{OH}$ setting as early as possible in sick leave due to common mental disorders. RTW can be considerably faster if collaborative care networks are set up in the $\mathrm{OH}$ setting in which the $\mathrm{OP}$ and a consultant psychiatrist work together in diagnosis and treatment of common mental disorders.

\section{Research implications}

These findings warrant further research of psychiatric consultation in employees on sick leave with mental disorders. In research aimed at evaluation of RTW, a follow up method should be developed enabling more precise monitoring of dates and extent of RTW. An early intervention should be evaluated and specific attention to time to RTW is needed. A trial is underway to establish RTW and cost effectiveness of such a collaborative care model for depressive disorder in the $\mathrm{OH}$ setting. ${ }^{36}$

\section{Policy implications}

For insurance companies covering absenteeism, the shorter time to RTW established by psychiatric consultation might enhance the willingness to arrange for easily accessible psychiatric consultation for the OP setting in an early phase of sickness absence due to common mental disorders. For companies, faster RTW leads to lower costs and enhanced productivity. This will enhance the willingness of employers to invest in contracts providing such psychiatric consultation care for their employees.

\section{Acknowledgments and disclosure}

- The authors of this article have no financial interest related to this research.

- Ethics approval for this trial was given by the METIGG Ethical Medical Committee.

- This trial was funded by the Aladdin research program and the sponsors did not play a role in the collection, analysis, and interpretation of data; in the writing of the report; and in the decision to submit the article for publication.

- The researchers were independent from funders.

\section{References}

1. Henderson M, Glozier N, Holland EK. Long term sickness absence. BMJ. 2005;330:802-803.

2. Bilsker D, Wiseman S, Gilbert M. Managing depression-related occupational disability: a pragmatic approach. Can J Psychiatry. 2006;51: 76-83.

3. Bowling A. What things are important in people's lives? A survey of the public's judgements to inform scales of health related quality of life. Soc Sci Med. 1995;41:1447-1462.

4. Nederlands Instituut van Psychologen (NIP), Landelijke Vereniging van Eerstelijnspsychologen (LVE). Werk en Psychische Klachten. Richtlijn Voor Psychologen. Amsterdam, The Netherlands:NIP/LVE; 2005. 
5. Bijl RV, Ravelli A, van Zessen G. Prevalence of psychiatric disorder in the general population: results of The Netherlands Mental Health Survey and Incidence Study (NEMESIS). Soc Psychiatry Psychiatr Epidemiol. 1998;33:587-595.

6. Alonso J, Angermeyer MC, Bernest S, et al; ESEMeD/MHEDEA 2000 Investigators; European Study of the Epidemiology of Mental Disorders. (ESEMeD) project. Prevalence of mental disorders in Europe: results from Euopean Study of the Epidemiology of Mental Disorders (ESEMeD) project. Acta Psychiatr Scand. 2004;109 Suppl 420:21-27.

7. De Waal MWM, Arnold IA, Eekhof JAH, van Hemert AM. Somatoform disorders in general practice: prevalence, functional impairment and comorbidity with anxiety and depressive disorders. Br J Psychiatry. 2004; 184:470-476.

8. Kroenke K, Spitzer RL, Williams JB, et al. Physical symptoms in primary care. Predictors of psychiatric disorders and functional impairment. Arch Fam Med. 1994;3:774-779.

9. van der Feltz-Cornelis CM, Dyck van R. The notion of somatisation: an artefact of the conceptualization of Body and Mind. Psychother Psychosom. 1997;66:117-127.

10. van der Feltz-Cornelis CM. Unexplained or undiagnosed? To a DSM-V for somatoform disorder. Comment on van Dieren and Vingerhoets. [In Dutch] [Onverklaard of ondoordacht? Naar een DSM-V van somatoforme stoornissen]. Tijdschrift voor Psychiatrie. 2007;11: 839-843.

11. Murray CJ, Lopez AD. Alternative projections of mortality and disability by cause 1990-2020: Global Burden of Disease Study. Lancet. 1997;349:1498-1504.

12. Nederlandse Vereniging voor Arbeids- en Bedrijfsgeneeskunde (NVAB). Module Depressie en Arbeid. Utrecht, The Netherlands: NVAB, 2005.

13. Prins R, van der Burg C, Heijdel W. Final report of the Subcommittee on mental problems. [Eindrapport Subcommissie psychische klachten.] [In Dutch] January 2005.

14. Smit F, Willemse G, Koopmanschap M, Onrust S, Cuijpers P, Beekman A. Cost-effectiveness of preventing depression in primary care patients: randomised trial. Br J Psychiatry. 2006;188:330-336.

15. Bijl RV, Ravelli A. Psychiatric morbidity, service use, and need for care in the general population: results of The Netherlands Mental Health Survey and Incidence Study. Am J Public Health. 2000;90:602-607.

16. Kruijshaar ME, Hoeymans N, Bijl RV, Spijker J, Essink-Bot ML. Levels of disability in major depression: findings from the Netherlands Mental Health Survey and Incidence Study (NEMESIS). JAffect Disord. 2003;77:53-64.

17. Mergl R, Seidscheck I, Allgaier AK, Moller HJ, Hegerl U, Henkel V. Depressive, anxiety, and somatoform disorders in primary care: prevalence and recognition. Depress Anxiety. 2007;24:185-195.

18. Leon AC, Olfson M, Portera L. Service utilization and expenditures for the treatment of panic disorder. Gen Hosp Psychiatry. 1997; 19:82-83

19. Brouwers EP, Tiemens BG, Terluin B, Verhaak PF. Effectiveness of an intervention to reduce sickness absence in patients with emotional distress or minor mental disorders: a randomized controlled effectiveness trial. Gen Hosp Psychiatry. 2006;28:223-229.

20. Comes L, van Eekeren A, de Leeuw F, Meekes M, van de Plassche H, van Santen A. Terugkeer naar het werk. Draaiboek voor trainers. Utrecht, The Netherlands Trimbos-instituut, 2005.

21. Landelijke Stuurgroep Multidisciplinaire Richtlijnontwikkeling in de GGZ. Multidisciplinaire richtlijn angststoornissen 2003 : richtlijn voor de diagnostiek, behandeling en begeleiding van volwassen clienten met een angststoornis. Utrecht, The Netherlands Trimbos-instituut; 2003.

22. Wamel AV, Verburg H, Meeuwissen J, Voordouw I, Velde VVD. [National Programme for anxiety disorders.] Landelijk basisprogramma angststoornissen. [In Dutch] Utrecht, The Netherlands Trimbos-instituut; 2005.

23. Terluin B, van Heest FB, van der Meer K, et al. NHG-Standaard Angststoornissen. Huisarts Wet. 2004;47:26-37.
24. van Marwijk HWJ, Bijl D, van Gelderen M, de Haan M. Dutch College of General Practitioners Guideline for Depression, first revision [NHG-Standaard Depressieve stoornis (depressie). Eerste herziening. In Dutch]. Huisarts Wet. 2003;614-623.

25. van Marwijk HWJ, Bijl D, van Gelderen M, de Haan M. Dutch College of General Practitioners Guideline for Depression, first revision [NHG-Standaard Depressieve stoornis (depressie). Eerste herziening. In Dutch]. Huisarts Wet. 2003;614-623.

26. CBO, Trimbos-Institute. Multidisciplinary Guideline Depressive Disorder [Multidisciplinaire Richtlijn Depressie]. [In Dutch]. Utrecht: Trimbos-instituut; 2005.

27. Ormel J, Bartel M, Nolen WA. [Undertreatment of depression; causes and recommendations]. Ned Tijdschr Geneeskd. 2003;147: 1005-1009.

28. Schene AH, Koeter MW, Kikkert MJ, Swinkels JA, McCrone P: Adjuvant occupational therapy for work-related major depression works: randomized trial including economic evaluation. Psychol Med. 2007:37:351-362.

29. Blonk RW, Brenninkmeijer V, Lagerveld SE, Houtman ILD: Return to work: A comparison of two cognitive behavioural interventions in cases of work-related psychological complaints among the self-employed. Work Stress. 2006;20:129-144.

30. van der Klink JJ, Blonk RW, Schene AH, van Dijk FJ: Reducing long term sickness absence by an activating intervention in adjustment disorders: a cluster randomised controlled design. Occup Environ Med. 2003;60:429-437.

31. Schene AH, van Weeghel J, van der Klink J, van Dijk FJH. Psychische aandoeningen en arbeid: de interventies. Psychische Aandoeningen en Arbeid, Houten The Netherlands: Bohn Stafleu Van Loghum; 2005. p. 251-269.

32. Nieuwenhuijsen K, Verhoeven AC, Bültmann U, Neumeyer-Gromen A, van der Feltz-Cornelis $\mathrm{CM}$. Interventions to improve occupational health in depressed people. Cochrane Database Syst Rev. 2006;4: CD006237.

33. Nederlandse Vereniging voor Arbeids- en Bedrijfsgeneeskunde (NVAB). Handelen van de bedrijfsarts bij werknemers met psychische klachten. Richtlijn voor bedrijfsartsen. Eindhoven, The Netherlands: NVAB; 2000.

34. STECR. Werkwijzer aanpak lichamelijk onverklaarde klachten en somatisatie. Nov 2006.

35. Gezondheidsraad. Evaluate, treat, coaching. Behandelen, begeleiding. In Dutch: Den Haag, The Netherlands: Gezondheidsraad; 2000.

36. Brouwers EPM, Tiemens BG, Terluin B, Verhaak PFM. Effectiveness of an intervention to reduce sickness absence in patients with emotional distress or minor mental disorders: a randomized controlled effectiveness trial. Gen Hosp Psychiatry. 2006;28:223-229.

37. Vlasveld MC, Anema JR, Beekman ATF, et al. Multidisciplinary collaborative care for depressive disorder in the occupational health setting: design of a randomised controlled trial and cost effectiveness study. $B M C$ Health Serv Res. 2008; 8:99.

38. van der Feltz-Cornelis CM, Van Oppen P, Adèr HJ, van Dyck R. Randomised controlled trial of a collaborative care model with psychiatric consultation for persistent medically unexplained symptoms in general practices. Psychother Psychosom. 2006;75:282-289.

39. van der Feltz-Cornelis CM, van Os TWDP, van Marwijk HWJ, Leentjens AFG. Effect of psychiatric consultation models in primary care. A systematic review and meta-analysis of randomized clinical trials. J Psychosom Res. 2010;68:521-523.

40. van der Feltz-Cornelis CM, Adèr HJ. Randomization in psychiatric intervention research in the general practice setting. Int $J$ Methods Psychiatr Res. 2000;9(3):136-144.

41. van der Feltz-Cornelis CM, Meeuwissen JAC, De Jong FJ, Hoedeman R, Elfeddali I. Study protocol. Randomised controlled trial of a psychiatric consultation model for treatment of common mental disorder in the occupational health setting. BMC Health Serv Res. 2007;7:29.

42. Moher D, Schulz KF, Altman DG. The CONSORT statement: revised recommendations for improving the quality of reports of parallel-group randomised trials. Lancet. 2001;357(9263):1191-1194. 
43. Altman DG, Schulz KF, Moher D, et al. The revised CONSORT statement for reporting randomized trials: explanation and elaboration. Ann Intern Med. 2001;134(8):663-694.

44. Spitzer RL, Kroenke K, Williams BW. Validation and utility of a selfreport version of PRIME-MD. The PHQ primary care study. J AMA 2006;282:1737-1744.

45. van Groos GAS. Short guideline for diagnostic criteria of the DSMIV-TR. Beknopte handleiding bij de Diagnostische criteria van de DSM$I V-T R$. In Dutch: Liss, The Netherlands: Swets and Zeitlinger; 2001.

46. Speckens AEM, Spinhoven P, Sloekers PPA, Bolk JH, van Hemert AM. A validation study of the Whithely Index the illness attitude scales and the somatosensory amplification scale in general medical and general practice patients. J Psychosom Res. 1996;40(1):95-104.

47. van der Feltz-Cornelis CM, Wijkel D, Verhaak PF, Collijn DH, Huyse FJ, van Dyck R. Psychiatric consultation for somatizing patients in the famility practice setting: a feasibility study. Int J Psychiatry Med. 1996;26:223-239.

48. Ware JE Jr, Sherbourne CD. The MOS 36-item short-form health survey (SF-36). I. Conceptual framework and item selection. Med Care. 1992; 30:473-483.

49. EuroQol Group. Eq-5D User Guide. Rotterdam, The Netherlands: Sanders Instituut, EUR; 1995.

50. Lamers LM, Stalmeier PFM, McDonnel JM, Krabbe PFM, van Busschbach JJ. Measuring quality of life in economical evaluations: the Dutch EQ-5D tariffs. Kwaliteit van leven meten in economische evaluaties: het Nederlands EQ-5D-tarief. In Dutch: Nederlands Tijdschrift voor geneeskunde. 2005;149:1574-1579.

51. EuroQol Group. EuroQol- a new facility for the measurement of healthrelated quality of life. Health Policy. 1990;16(3):199-208.

52. Arrindell WA, Ettema JHM. SCL-90. Guide for a multidimenstional psychopathology indicator. Handleiding bij een multidimensionele psychopathologie indicator. In Dutch: Lisse, THe Netherlands: Swets Tests Services; 1992
53. Bakker IM, Terluin B, van Marwijk HWJ, et al. A cluster-randomized trial evaluating an intervention for patients with stress-related mental disorders and sick leave in primary care. PLoS Clin Trials. 2007;2(6):e26.

54. Brouwers EPM, Tiemens BG, Terluin B, Verhaak PFM. Effectiveness of an intervention to reduce sickness absence in patients with emotionaldistress or minor mental disorders: a randomised controlled effectiveness trial. Gen Hosp Psychiatry. 2006;28:223-229.

55. Snijders T, Bosker R. Multilevel Analysis. An introduction to basic and advanced multilevel modelling. London, UK: Safe Publications, 1999.

56. Cochran WG. Sampling techniques. Third Edition. New York, NY: Wiley; 1977.

57. Keny SN, Bland JM. Analysis of a trial randomised in clusters. BMJ. 1988 3;316(7124):54.

58. International Standard Classification of Occupations (ISCO). ISCO88. Available from; http://www.ilo.org/public/english/bureau/stat/isco/ isco88/major.htm. Accessed March 10, 2010.

59. American Psychiatric Association Diagnostic and Statistical Manual of Mental Disorders: DSM-IV. Washington: APA; 1994.

60. van der Feltz-Cornelis CM, Knispel A, Elfeddali I. Treatment of mental disorder in the primary care setting in the Netherlands in the light of the new reimbursement system: a challenge? Research paper. Int $J$ Integr Care. 2008;8:e.56.

61. Meeuwissen JAC, van der Feltz-Cornelis CM, van Marwijk HWJ, Rijnders P, Donker M. A stepped care programme for depression management: An uncontrolled pre-post study in primary and secondary care in the Netherlands. Int J Integr Care. 2008;8:e.56.
Neuropsychiatric Disease and Treatment

\section{Publish your work in this journal}

Neuropsychiatric Disease and Treatment is an international, peerreviewed journal of clinical therapeutics and pharmacology focusing on concise rapid reporting of clinical or pre-clinical studies on a range of neuropsychiatric and neurological disorders. This journal is indexed on PubMed Central, the 'PsycINFO' database and CAS, and is the official

\section{Dovepress}

journal of The International Neuropsychiatric Association (INA). The manuscript management system is completely online and includes a very quick and fair peer-review system, which is all easy to use. Visit http://www.dovepress.com/testimonials.php to read real quotes from published authors. 